\title{
Estradiol and Tryptophan Depletion Interact to Modulate Cognition in Menopausal Women
}

\author{
Zenab Amin*,', Ralitza Gueorguieva',2, Angela Cappiello', Kathryn A Czarkowski', Stephanie Stiklus', \\ George M Anderson ${ }^{3}$, Frederick Naftolin ${ }^{4}$ and C Neill Epperson ${ }^{1,4}$ \\ 'Department of Psychiatry, Yale University School of Medicine, New Haven, CT, USA; ${ }^{2}$ Department of Epidemiology and Public Health, Yale \\ University School of Medicine, New Haven, CT, USA; ' ${ }^{Y}$ ale Child Study Center, Yale University School of Medicine, New Haven, CT, USA; \\ ${ }^{4}$ Departments of Obstetrics, Gynecology and Reproductive Sciences, Yale University School of Medicine, New Haven, CT, USA
}

\begin{abstract}
Despite an abundance of data in animals, there is little research in humans regarding how estrogen and serotonin (5-HT) may interact to influence cognition. Through the use of estrogen treatment (ET) and tryptophan depletion (TRP-D) in a within-subject design involving healthy menopausal women, we have manipulated both estrogen and 5-HT in order to evaluate their individual and joint effects. Although neither manipulation influenced visuospatial learning, a significant interaction suggested that estrogen exerted a protective effect on verbal memory, such that TRP-D impaired performance to a greater extent before the administration of ET. In consonance with this finding, ET was associated with a small, but positive mood effect on the day following active TRP-D. In addition, ET significantly improved letter-cued verbal fluency with and without TRP-D. Finally, time since last menstrual period was significantly associated with verbal memory scores, such that longer length of hypogonadism resulted in decreased verbal memory performance. These data support the interaction of estrogen and 5-HT in nonreproductive behavior in humans as well as highlight the role of ovarian steroids in cognition. Neuropsychopharmacology (2006) 3 I, 2489-2497. doi: I 0. I038/sj.npp. I 30 I I 4; published online 7 June 2006
\end{abstract}

Keywords: tryptophan depletion; serotonin; estrogen; menopause; cognition; verbal memory

\section{INTRODUCTION}

Several studies have reported that the menopause may be marked by changes in cognition and mood in addition to well-characterized vasomotor and urogenital symptoms (Devi et al, 2005; McVeigh, 2005; Peeyananjarassri et al, 2006; Schnatz et al, 2006). While the administration of estradiol can relieve depressive symptoms (Schmidt et al, 2000; Soares et al, 2001) and may improve cognitive symptoms (Sherwin, 2003), particularly when used early in the menopausal transition, the mechanisms by which estrogen affects cognition and mood are still unclear. There is evidence of estrogen's interaction with the neurotransmitter serotonin (5-HT; reviewed by Amin et al, 2005), which is hypothesized to be involved in depression and various cognitive processes. Although research in animals suggests that estrogen may enhance 5-HT transmission, there is little information about estrogen-5-HT interactions in humans. Studies of estrogen treatment (ET) in menopausal women

\footnotetext{
*Correspondence: Dr Z Amin, Department of Psychiatry, Yale University School of Medicine, 100 York Street, Suite 2H, New Haven, CT 065 I I, USA, Tel: + I 203764 9945, Fax: + I 203764 9990, E-mail: zenab.amin@yale.edu

Received 27 December 2005; revised 30 March 2006; accepted 3 May 2006

Online publication: 10 May 2006 at http://www.acnp.org/citations/ Npp05 I006050762/default.pdf
}

indicate increased 5-HT activity (Sherwin and SuranyiCadotte, 1990; Halbreich et al, 1995; Lippert et al, 1996; van Amelsvoort et al, 2001), improved mood (Schmidt et al, 2000; Soares et al, 2001), and, despite some inconsistencies across measures and hormone regimens, improved performance in cognitive domains such as verbal learning and memory (Hogervorst et al, 2000; LeBlanc et al, 2001; Rice and Morse, 2003). In addition, estrogen-induced changes in the 5-HT system have been found coincident with mood or cognitive changes (Sherwin and Suranyi-Cadotte, 1990; Kugaya et al, 2003). Thus, the literature suggests a correlation between estrogen and 5-HT activity and a change in mood or cognition in humans, but causation is unclear. However, by manipulating both estrogen and 5-HT in humans, it may be possible to evaluate their individual and joint effects.

The acute tryptophan depletion (TRP-D) paradigm, a manipulation that results in rapid reduction of brain TRP and 5-HT levels, has been successfully used in human studies as a probe of central 5-HT function. Sex differences in the behavioral response to acute TRP-D have been identified, suggesting hormonal influences on the 5-HT system. For example, a positron emission tomography study demonstrated that the rate of 5-HT synthesis decreased significantly more in women than in men undergoing TRPD (Nishizawa et al, 1997). In addition, a study of 20 healthy women found that TRP-D resulted in significant worsening 
of mood, although data from healthy men had shown no significant change (Ellenbogen et al, 1996).

The use of TRP-D in conjunction with ET would help to define a pathway by which estrogen-5-HT interactions may influence menopausal symptoms. ET has been associated with improved verbal memory (Resnick et al, 1998; Wolf et al, 1999; Maki et al, 2001; Shaywitz et al, 2003), semantic recall (Henderson et al, 1996), and figural memory (Resnick et al, 1998). In contrast, TRP-D has repeatedly been shown to impair learning, particularly verbal memory (Park et al, 1994; Schmitt et al, 2000; McAllister-Williams et al, 2002). Other studies have found response inhibition, decisionmaking, and processing of reward cues to be disrupted by TRP-D as well (Park et al, 1994; Rogers et al, 1999, 2003; Murphy et al, 2002). However, focused attention (Schmitt et al, 2000; Gallagher et al, 2003) and verbal fluency (Schmitt et al, 2000) measures have been improved by the procedure.

Whereas estrogen may be an effective treatment for certain mood disorders (reviews by Epperson et al, 1999; Halbreich and Kahn, 2001), TRP-D has been associated with depressive relapse (Delgado et al, 1990). In healthy populations, only those who are vulnerable to affective disorders, for example, as indicated by family history or 5-HT transporter genotype, are likely to experience mood-lowering effects of TRP-D (Benkelfat et al, 1994; Klaassen et al, 1999; Neumeister et al, 2002). However, because female gender is also a predictor of mood response to TRP-D (Booij et al, 2002), menopausal women may form a vulnerable group in which an interaction between estrogen and 5-HT may be observed with regard to mood.

Differences in estrogen response are possible depending on how recently the menopause took place. Although reviews and meta-analyses suggest a positive, albeit modest, effect of menopausal hormone therapy (HT) on verbal memory, attention, and reasoning, and associate it with a decreased risk of dementia (eg, Hogervorst et al, 2000; Rice and Morse, 2003), most reports also cite methodological differences across studies. For example, there may be adverse effects depending on the type of HT or timing of HT use (Espeland et al, 2004). Some meta-analyses suggest that mainly symptomatic perimenopausal women (who are within 12 months of their last menstrual period (LMP)) experience cognitive improvement as a result of HT (Yaffe et al, 1998; LeBlanc et al, 2001). This may relate to coincident improvement in menopausal symptoms such as insomnia, but recent evidence suggests that estrogen use early during menopause can exert positive effects on cognition (Sherwin, 2003; Bagger et al, 2005). Similarly, whereas estrogen administration does not appear effective in the treatment of major depression in postmenopausal women (Morrison et al, 2004), two double-blind placebo-controlled studies (Schmidt et al, 2000; Soares et al, 2001) have shown that estradiol administration was effective in treating perimenopausal women experiencing major or minor depression.

Thus, we hypothesize that ET will have a protective effect on cognition in menopausal women undergoing TRP-D. As both estradiol and 5-HT modulate mood, menopausal women may manifest increased vulnerability (lowering of mood) to TRP-D before ET than after ET. In addition, analyses investigated whether time since LMP influenced the degree of ET effects.

\section{MATERIALS AND METHODS}

\section{Participants}

Participants were recruited via advertisements in the New Haven, CT area. Twenty menopausal women were admitted to the study after a complete medical and psychiatric history had been obtained. All participants were free of past or present psychiatric illness, as determined by a structured clinical interview (SCID; First et al, 1997). All subjects used English as their primary language, had a complete physical, gynecological (with PAP smear), and neurological examination at the time of initial evaluation, were not already on ET, and had no medical contraindication to ET. Written informed consent was obtained from all subjects.

Although previous hormone use was not exclusionary, one participant was withdrawn from analyses because of having used HT for 7 years, making her an outlier with respect to length of HT exposure after menopause. Of the remaining 19 participants (mean age $=52.3$ years, $S D=5.8$ ), only four women had any prior exposure to ET, which was minimal in duration: two women had used ET for a few weeks several years before participation and two women had used ET for a few months, but one had discontinued use 5 years before study participation and the other stopped 6 months before participation. One participant had also briefly used the selective estrogen receptor modulator raloxifene. Included in the sample were 11 postmenopausal women (no menstrual cycles for at least 1 year) and eight perimenopausal women (irregular menses of either $<21$ days or $>35$ days from the previous 6 months to 1 year and follicle-stimulating hormone level $\geqslant 20 \mathrm{IU} / \mathrm{l})$.

Time since LMP served as a marker for the period of absence of ovarian estrogen and ranged from 1 to 156 months ( mean $=32.79, \mathrm{SD}=49.51$; median $=12$ ). Because their exposure was minimal, for the two women with postmenopausal estrogen exposure, LMP was considered to be the last menses before any hormone use. Two participants had a partial hysterectomy before menopause, which involves removal of the uterus, but leaves ovaries intact. Because these women experienced the transition to menopause at an unidentifiable time point, LMP for them was calculated as having occurred at the mean age of menopause in the United States (52 years; Reynolds and Obermeyer, 2005).

Five women did not participate in the post-ET TRP-D sequences: three women chose to discontinue ET owing to physical side effects, one chose not to begin ET, and one decided not to complete the study. However, by using mixed-effect models (see Data analysis below), these participants need not be excluded from analyses (Gueorguieva and Krystal, 2004).

\section{TRP-D}

Subjects took part in four TRP-D test sequences: the first two took place 1 week apart, before 8 weeks of an open trial of ET, and the remaining two test sequences took place 1 week apart, during the last 2 weeks of ET. Each 3-day TRP$\mathrm{D}$ test sequence was comprised of 1 day of a $160 \mathrm{mg} /$ day low-TRP diet (Test Day 1), followed the next morning by administration of an amino-acid mixture (Test Day 2), and 
concluded the next morning with a final assessment session over the telephone (Test Day 3). The amino-acid mixture consisted of a $350 \mathrm{ml}$ amino-acid drink flavored with chocolate syrup (containing L-histidine, L-isoleucine, L-leucine, L-lysine, L-phenylaline, L-serine, L-proline, L-threonine, L-tyrosine, L-valine, L-alanine, and glycine) and 25 capsules containing more noxious-tasting amino acids (methionine, arginine, and cysteine). For each pair of TRP-D tests (before and after ET), one of the test sequences included L-TRP supplementation (sham depletion), whereas the other did not (active depletion). The order of the tests (sham $v s$ active depletion) was double-blind and randomized.

\section{TRP and Hormone Assays}

In order to monitor plasma TRP levels, blood sampling took place on the morning of Day 1 and in the morning and afternoon ( $+5 \mathrm{~h}$ after amino-acid ingestion) of Day 2 . Free and total plasma TRP levels were determined using a high-performance liquid chromatographic-fluorometric system after the addition of 5-hydroxytryptophan internal standard (final concentration $5 \mu \mathrm{g} / \mathrm{ml}$ ) and perchloric acid by direct injection (Anderson et al, 1981). Both free and total plasma TRP levels were determined with within-assay and assay-to-assay coefficients of variation of less than 5 and $10 \%$, respectively. Detection limits for both free and total TRP were less than $0.01 \mu \mathrm{g} / \mathrm{ml}$. Owing to an error in storage, blood samples for the analysis of TRP levels were unavailable for four participants (mean age $=47.0$ years, $\mathrm{SD}=3.6$; mean $\mathrm{LMP}=9.25, \mathrm{SD}=8.46)$. As there were no adverse events that may have influenced the TRP-D test, their mood and cognitive data have been included in statistical analyses.

Estradiol levels were evaluated by blood drawn on the morning of Day 1. Serum estradiol was measured by competitive immunoassay using a chemiluminescent substrate in a commercially available kit provided by Diagnostic Productions Corporation, Los Angeles, CA. The sensitivity for this kit is $15 \mathrm{pg} / \mathrm{ml}$ and the approximate coefficient of variability at ranges observed in this study is $11-13 \%$.

\section{Mood and Cognitive Assessments}

Clinician and patient ratings were performed in the morning of Day 1, morning, afternoon $(+5 \mathrm{~h})$, and end $(+7 \mathrm{~h})$ of Day 2, and, to examine the possibility of any persistent effects of TRP-D, in the morning of Day 3 . Ratings consisted of the Hamilton Depression Rating Scale (HDRS; Hamilton, 1960) and Profile of Mood States (POMS; McNair et al, 1992). Cognitive measures were performed in the afternoon of Day 2 ( $+5 \mathrm{~h}$ after amino-acid ingestion) of each test sequence. Testing consisted of verbal fluency (Benton's Controlled Oral Word Association; Benton et al, 1994), verbal associate learning (Wechsler Memory Scale Paired Associates subtest; Wechsler, 1987), verbal logical memory (Wechsler Memory Scale Paragraph Recall subtest; Wechsler, 1987), and visuospatial memory (Visual-Spatial Learning test; Malec et al, 1991). Equivalent, but not identical, versions of each learning and memory test were available (Wechsler, 1987; Malec et al, 1991) and administered at each of the four test sessions. Verbal fluency involved one cue letter ( $, \mathrm{T}, \mathrm{R}$, or $\mathrm{P})$ and one cue category (vegetables, animals, fruits, or careers) at each test session, and the number of words produced by the participant in 1 min determined her score. These letters and categories have previously been found to be approximately equivalent in difficulty (Cauthen, 1978; Benton et al, 1994; Ravdin et al, 2003). Paired-associates score reflected the mean number of correct words produced across the first three presentations (out of a total of six presentations) of a set of eight pairs of words. The paragraph recall test involved the sum score of two paragraphs at each session. Visuospatial learning tested recognition of nonverbal figures and recall of their locations. A delayed measure of all three memory tests (paired-associates, paragraph recall, and visuospatial learning) took place $30 \mathrm{~min}$ after the initial test. Test versions were not randomized.

\section{Estrogen Treatment}

After completing the first two TRP-D test sequences, participants underwent transdermal estradiol treatment (Vivelle-Dot ${ }^{\circledR} \quad 0.075-0.15 \mathrm{mg} /$ day donated by Novogyne Pharmaceutical Corporation, Miami, FL) for 8 weeks. Following completion of 6 weeks of ET, the subjects participated in the last two TRP-D test sequences. At the end of the last two TRP-D test sequences, subjects received medroxyprogesterone for 14 days at a dose of $5 \mathrm{mg} /$ day, to convert the endometrium to a secretory stage that was shed, removing the proliferative effects of ET.

\section{Data Analysis}

Data were assessed for normality before analysis using normal probability plots and Kolmogorov-Smirnov test statistics, and variables were log-transformed as necessary. Analyses of plasma total and free TRP were performed with mixed effects models with fixed effects of condition (active TRP-D/sham TRP-D), treatment (pre-estrogen/postestrogen), time since LMP (in months), time point (Day 1, Day 2 AM, Day $2+5 \mathrm{~h}$ ), and all possible interactions. Both mood measures were similarly analyzed with fixed effects of condition (active TRP-D/sham TRP-D), treatment (pre-estrogen / postestrogen), time since LMP (in months), time point (Day 1, Day $2 \mathrm{AM}$, Day $2+5 \mathrm{~h}$, Day $2+7 \mathrm{~h}$, and Day 3), and all possible interactions. Plasma estradiol and cognitive measures were analyzed with fixed effects of condition (active TRP-D/sham TRP-D), treatment (preestrogen/postestrogen), time since LMP (in months), and all possible interactions. Best-fitting variance-covariance structure was selected according to the Akaike's and Schwartz' information criterions. Nonsignificant interactions were dropped from the models for parsimony. Residual plots were used to check the model assumptions. For mood and cognitive measures, age- and time-specific estradiol levels were considered as covariates and were dropped from the model if nonsignificant at $p=0.10$ level. Bonferroni correction was applied within but not between hypotheses. Analyses of immediate $v s$ delayed measures were considered separate hypotheses according to the previous TRP-D studies finding differences between immediate and delayed memory (Riedel et al, 1999; Schmitt et al, 2000; Harrison et al, 2004), and therefore were not adjusted for multiple comparisons. The two delayed outcomes of the 
Visual-Spatial Learning test were analyzed nonparametrically using the approach of Brunner et al (2002).

\section{RESULTS}

\section{TRP and Estrogen Assays}

Both total and free plasma levels of TRP significantly decreased between the sham and active condition regardless of $\mathrm{ET}, \mathrm{F}(1,2.69)=23.68, p=0.04$ and $\mathrm{F}(1,31.2)=13.38$, $p=0.002$, respectively (Figure 1 ). Free TRP levels showed a significant condition $\times$ time point interaction, $\mathrm{F}(2,11.1)=$ 20.45, $p=0.0004$, such that active depletion resulted in significantly lower levels only on Day 2 in the afternoon ( $5 \mathrm{~h}$ following ingestion of amino acids). On Day 1 (before the low TRP diet) and in the morning of Day 2 (before amino-acid ingestion), the differences were not statistically significant.

There was also a significant interaction, $\mathrm{F}(1,39.8)=8.45$, $p=0.012$, such that the magnitude of the effect of TRP-D condition on free TRP levels was higher before treatment than after: $\mathrm{F}(1,22.5)=11.39, p=0.003$ pre-ET and $F(1,20.3)=7.43, p=0.013$ post-ET. However, this was driven by higher mean free TRP levels pre-ET only on Day 1 of the active depletion sequence (before the low TRP diet) and similar reductions caused by the depletion procedure both pre- and post-treatment. Because there was no increased free TRP before the pretreatment sham depletion sequence, this finding is not believed to be indicative of ET effects on free TRP or a true interaction between ET and the TRP-D procedure. One participant vomited following amino-acid ingestion on both active depletion test days (after $4 \mathrm{~h}$ on the pre-ET test day and $2 \mathrm{~h}$ on the post-ET day), which resulted in a failure to decrease plasma TRP only on her post-ET depletion day. The results of the intentto-treat group analyses are reported and this participant's post-ET data minimally influenced group means for mood and cognitive data.

As expected, plasma estradiol level showed a significant effect of treatment such that levels pre-ET (mean = $31.72 \mathrm{pg} / \mathrm{ml}$ ) were significantly lower than post-ET (mean = $96.33 \mathrm{pg} / \mathrm{ml}), \mathrm{F}(1,24.7)=43.66, p<0.0001$. Active and sham TRP-D days did not differ with respect to estradiol level. There was also a significant effect of months since LMP,
$\mathrm{F}(1,14.6)=11.26, p=0.0045$, such that estradiol levels decreased as time since LMP increased. An interaction between treatment and time since LMP showed that the correlation between months since LMP and estradiol levels was more significantly negative pretreatment than post-treatment, $\mathrm{F}(1,25.9)=4.46, p=0.0445$. Thus, as may be expected, treatment decreased the influence of length of hypogonadism on estradiol levels.

\section{Mood Measures}

There were no significant effects of TRP-D or ET on total POMS score (an index of negative affect). HDRS scores showed a significant condition $\times$ treatment $\times$ time point interaction, $\mathrm{F}(4,135)=3.21, p=0.03$, which revealed that at Day 3 following active TRP-D, pre-ET scores $($ mean $=2.53)$ were higher than post-ET scores $($ mean $=0.6)$.

\section{Cognitive Measures}

Verbal associate learning. On the immediate pairedassociates test, there was a significant condition $\times$ treatment interaction, $\mathrm{F}(1,43.4)=4.23, p=0.046$, such that there was a significant effect of TRP-D before ET, F $(1,43.4)=10.90$, $p=0.002$, but not after ET, $\mathrm{F}(1,43.4)=0.03, p=0.87$ (Figure 2). With higher scores indicating better performance, scores (across conditions) on both the immediate and delayed paired-associates decreased as time since LMP

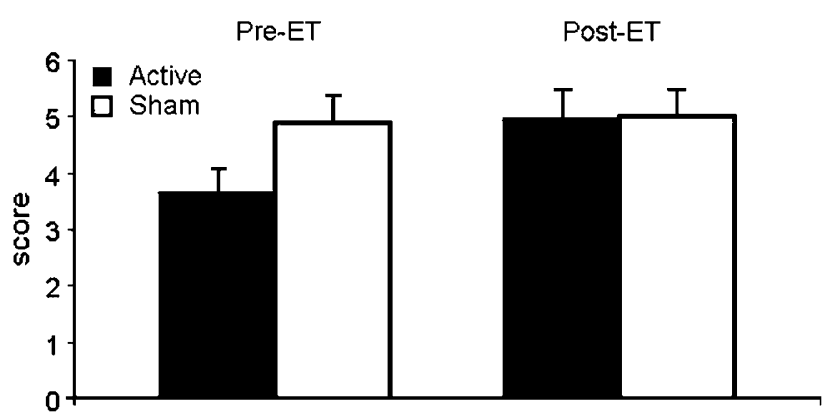

Figure 2 Interaction between ET and TRP-D on immediate pairedassociates score (mean $\pm \mathrm{SEM})$.
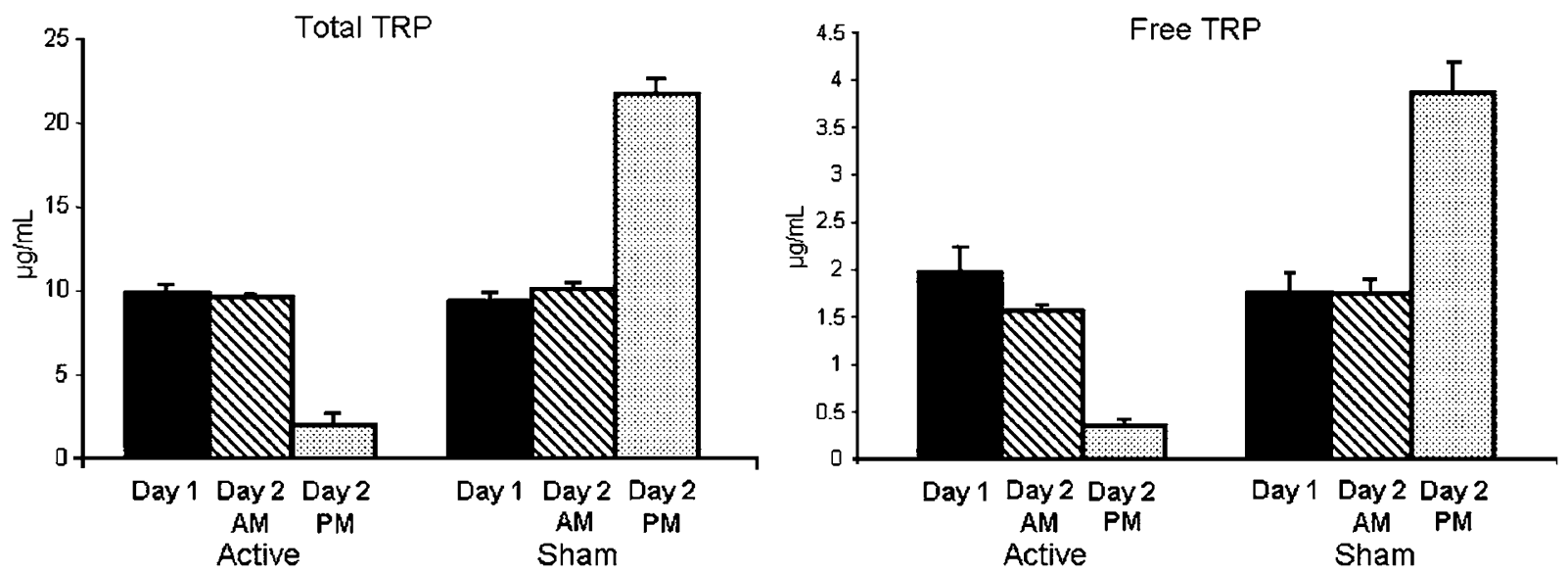

Figure I Total and free plasma TRP levels in active and sham depletion conditions, collapsing across estrogen condition (mean \pm SEM). 

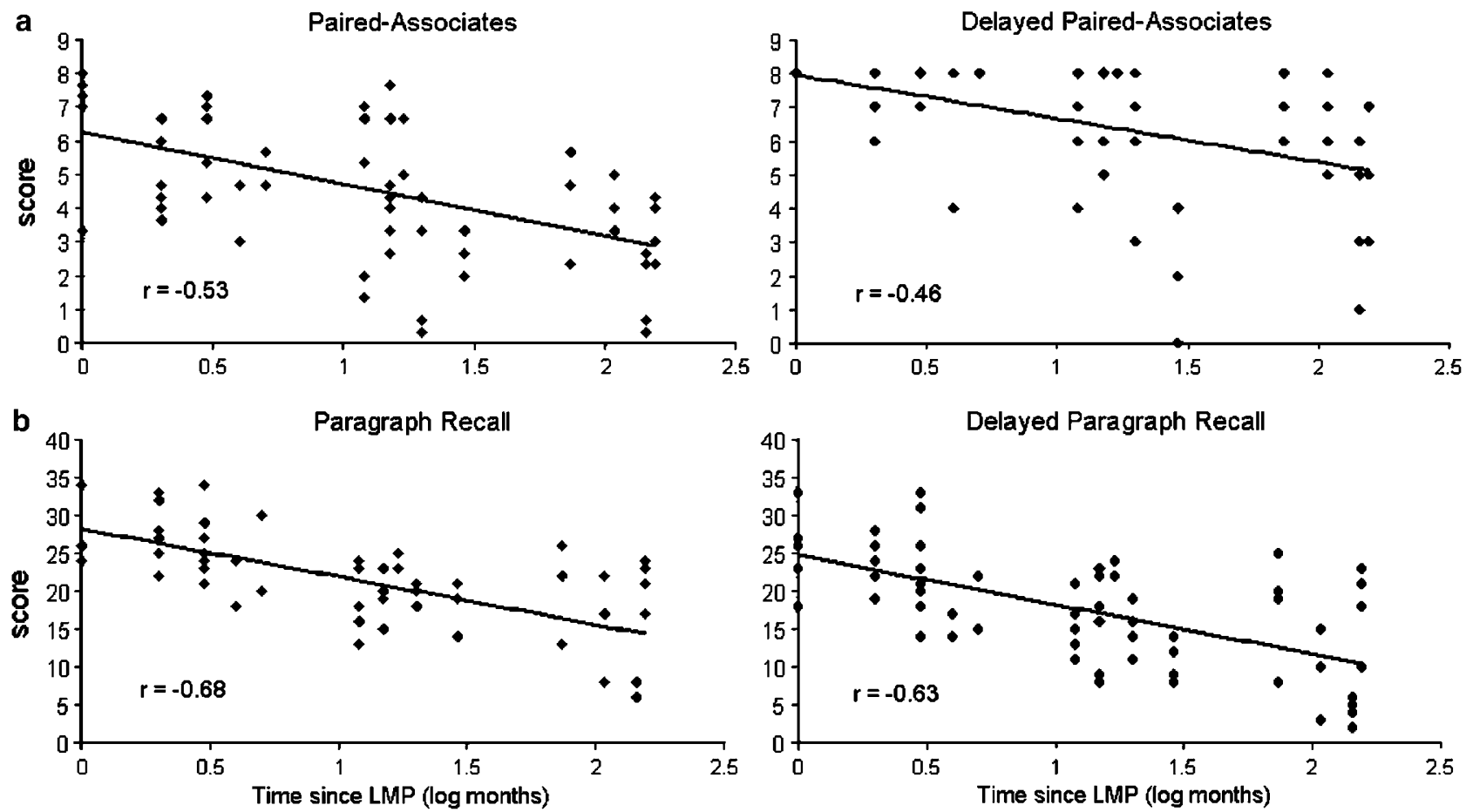

Figure 3 Relationship between verbal memory measures and time since LMP. (a) Negative correlations between immediate and delayed paired associates scores and time since LMP. (b) Negative correlations between immediate and delayed paragraph recall scores and time since LMP.

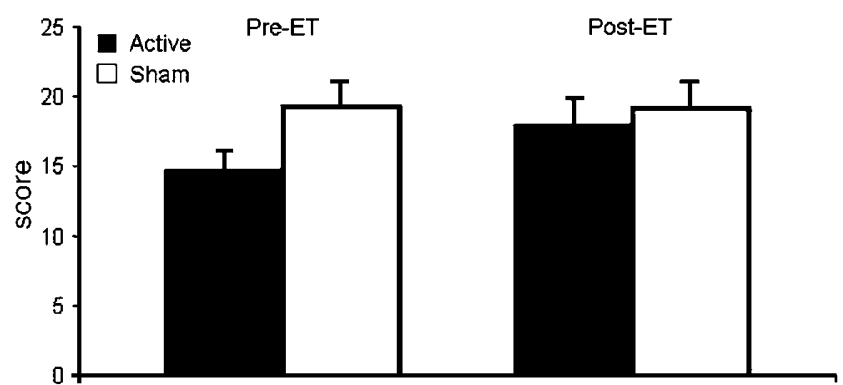

Figure 4 Effects of ET and TRP-D on delayed paragraph recall score (mean \pm SEM).

increased, $\mathrm{F}(1,15.4)=12.04, p=0.003$ and $\mathrm{F}(1,15.3)=6.62$, $p=0.021$ (Figure 3a). Delayed paired-associates scores showed no significant effect of TRP-D condition or estradiol treatment and more pairs were remembered correctly than for the immediate test (Figure 3a).

Verbal logical memory. Both immediate and delayed paragraph recall scores showed significant effects of time since LMP, such that scores across conditions decreased as time since LMP increased, $\mathrm{F}(1,15)=20.90, p=0.0004$ and $\mathrm{F}(1,15.3)=17.27, p=0.0008$, respectively (Figure $3 \mathrm{~b}$ ). In addition, there was a marginally significant condition $x$ treatment interaction for delayed paragraph recall, $\mathrm{F}(1,30)=$ $4.15, p=0.051$ : although ET significantly improved memory, $\mathrm{F}(1,27.7)=4.31, p=0.047$, and TRP-D significantly impaired memory, $\mathrm{F}(1,15.4)=9.31, p=0.008$, the effect of TRP-D was largely driven by pre-ET and not post-ET scores (Figure 4).
Table I Mean Verbal Fluency Scores

\begin{tabular}{llllll}
\hline & \multicolumn{2}{c}{ Category } & & \multicolumn{2}{c}{ Letter } \\
\cline { 2 - 3 } \cline { 5 - 6 } Condition & M & SD & & M & SD \\
\hline Pre-ET & & & & \\
$\quad$ Active depletion & 15.37 & 3.00 & & 17.11 & 4.69 \\
Sham depletion & 17.33 & 4.21 & & 15.44 & 4.64 \\
& & & & & \\
Post-ET & & & & \\
Active depletion & 16.86 & 4.55 & & 18.79 & 4.58 \\
Sham depletion & 17.43 & 4.57 & 18.00 & 6.36 \\
\hline
\end{tabular}

Verbal fluency. While there was no significant effect of TRP condition, there was a significant effect of ET on verbal fluency scores, $\mathrm{F}(1,28.5)=7.83, p=0.018$, such that post-ET scores when naming words beginning with a cue letter were higher across conditions. However, there were no significant effects on word fluency when given a cue category (Table 1).

Visuospatial memory. On the Visual-Spatial Learning test, there were no significant effects of TRP-D or ET on immediate or delayed recognition of nonverbal figural designs or recall of their location.

\section{DISCUSSION}

By manipulating both TRP and estradiol levels, we investigated the effects of estrogen-5-HT interactions on 
cognition and mood in healthy menopausal women. Verbal memory scores suggested a protective effect of ET on TRP-D-induced impairments. There was also a significant interaction with regard to mood, such that ET improved mood on the day after active TRP-D. In addition, ET had a significant positive effect on letter-cued verbal fluency. Finally, regardless of TRP-D, time since LMP was significantly negatively associated with verbal memory performance.

The degree to which plasma TRP levels were reduced was consistent with findings from others (eg, Delgado et al, 1990), and would be expected to result in a significant decrease in 5-HT synthesis and release. Although we found an increase in plasma TRP during sham depletion, this is consistent with previous studies using similar amino-acid mixtures (eg, Schmitt et al, 2000; McAllister-Williams et al, 2002). Whereas amino-acid mixtures lacking TRP significantly lower the TRP concentration relative to large neutral amino acids competing for transport across the blood-brain barrier, mixtures containing TRP have been shown to have no effect on this ratio or to decrease it slightly (Golightly et al, 2001; Kahkonen et al, 2002).

As hypothesized, significant effects of TRP-D and ET on verbal memory resulted in a protective effect of ET, such that paired-associates learning was only impaired by TRP-D before ET. A similar trend was identified in delayed paragraph recall score. ET has previously been associated with improved verbal memory (Resnick et al, 1998; Maki et al, 2001), including effects on paired associates and paragraph recall tests (Wolf et al, 1999; Shaywitz et al, 2003). In contrast, TRP-D impairs verbal memory (Park et al, 1994; Schmitt et al, 2000; McAllister-Williams et al, 2002). Our results support that impairments in verbal memory caused by rapid reductions in 5-HT may be ameliorated or inhibited by ET, which is consistent with animal literature, suggesting that estrogen can enhance 5-HT transmission in brain regions that are important for cognition (Amin et al, 2005). Thus, estrogen and 5-HT may have overlapping influences on neural pathways specific to verbal memory. Medial temporal lobe memory structures are implicated in both estrogen (Maki and Resnick, 2000; McEwen, 2002; Rapp et al, 2003) and 5-HT's (Riedel et al, 2003) effects on cognition. In addition, transcranial magnetic stimulation and neuroimaging studies indicate the involvement of areas of the left prefrontal cortex in verbal memory (Leube et al, 2001; Reber et al, 2002; Floel et al, 2004). Future research incorporating imaging paradigms may be used to examine where along this pathway estrogen and 5-HT may exert joint influences on verbal learning.

In healthy subjects, previous TRP-D studies have indicated impairment of memory consolidation (Riedel et al, 1999; Schmitt et al, 2000; Harrison et al, 2004), and thus delayed recall performance would be expected to be more affected than immediate recall. However, unlike paragraph recall scores, the effects of ET and TRP-D were significant only on immediate paired-associates recall and delayed scores were actually higher than immediate scores. This may be explained by the immediate paired-associates score being the mean of the first three of a total of six attempts at recalling a set of words (including six presentations of word pairs), whereas the delayed score represents recall $30 \mathrm{~min}$ after these attempts. Thus, practice effects may have influenced delayed paired-associates recall scores, but not delayed paragraph recall, resulting in the difference in findings.

Consistent with previous studies utilizing the TRP-D paradigm in healthy participants, we observed no main effects of TRP-D on mood (Schmitt et al, 2000; Stewart et al, 2002; Harrison et al, 2004). However, there was a significant interaction such that ET significantly improved HDRS score on the morning following active TRP-D. Although preliminary and not of clinical significance, our findings suggest that estrogen may exert a positive effect on mood in relation to TRP-D. Some previous studies have found TRP-D to affect mood the day after active depletion in drugfree patients (Delgado et al, 1994; Neumeister et al, 1997), which may explain why the interaction was significant after plasma TRP levels would have returned to normal. However, independent replication of our results would be valuable.

ET also improved verbal fluency scores, but only when participants were given a cue letter and not a cue category. Previous studies have suggested separate neural substrates underlying these phonemically $v s$ semantically based types of performance (Billingsley et al, 2004; Brickman et al, 2005). Healthy participants have been found to score higher on the category-cued test (Brickman et al, 2005), suggesting that this measure may be easier than the letter-cued test. Thus, it is possible that ET did not significantly improve category-cued performance because of a difficulty effect.

In contrast to the effects of ET, TRP-D did not significantly influence either verbal fluency measure. Previous studies investigating the effects of TRP-D on verbal fluency have found no change or improved performance (Schmitt et al, 2000; Stewart et al, 2002; Gallagher et al, 2003). This may be explained by the finding that TRP-D has little influence on executive function tasks (eg, Park et al, 1994; Gallagher et al, 2003) and verbal fluency measures have a large executive function component.

Neither ET nor TRP-D had significant effects on visuospatial learning. Although previous studies have suggested that estrogen may interfere with three-dimensional visuospatial processing (Hampson and Kimura, 1988; Hampson, 1990a, b), it may have no effect (Silverman and Phillips, 1993; Phillips and Silverman, 1997; Maki et al, 2001) or improve (Resnick et al, 1998; Smith et al, 2001) other types of figural or spatial processing tasks. While previous research has primarily investigated the effects of TRP-D on verbal learning and memory, studies have found no influence of TRP-D on spatial or pattern recognition (Park et $a l, 1994)$ and evidence for impairment of paired associate visual spatial learning (Park et al, 1994) and delayed pattern recognition (Rubinsztein et al, 2001). More research is necessary to determine the precise effects of ET and TRP-D on various forms of learning.

Time since LMP (controlling for age) was negatively associated with verbal memory scores. Circulating estradiol levels have previously been positively associated with verbal memory performance in healthy elderly women (Drake et al, 2000) and studies of verbal memory in surgically menopausal women have associated ET following surgery with protective effects (Sherwin, 1988; Phillips and Sherwin, 1992). Our finding that longer length of hypogonadism (and thus, decreased estrogen exposure) is signi- 
ficantly associated with decreased verbal memory score is consistent with these findings.

Methodological considerations regarding our findings are worthy of comment. Although our sample size was comparable to that of other investigations involving TRP-D, it is possible that some behavioral effects of TRP-D or ET went unrecognized. Because of the within-subject design of our study, there may have been practice effects on cognitive measures, resulting in a confound between practice effects and ET. This was minimized through the use of equivalent versions of each task on each test day. Although test versions were not randomized, active and sham TRP-D days were both double-blind and randomized. Nevertheless, replication of our current findings as well as future studies involving larger samples of menopausal women would be informative, especially with regard to differential effects of ET early and late in the menopausal transition.

In conclusion, we have replicated previous studies finding significant effects of TRP-D on verbal memory and extended these findings with evidence that estrogen may modulate these effects in menopausal women. We also found that ET improved verbal fluency and that time since LMP is associated with verbal memory performance. These data support the interaction of estrogen and 5-HT in cognition as well as highlight the important behavioral effects of ovarian steroids.

\section{ACKNOWLEDGEMENTS}

This study was funded in part by the National Institute of Mental Health (K23 MH01830-01 and KO2 MH73090; Epperson), Eli Lilly and Company, the Dana Foundation, and the Ethel F Donaghue Foundation. Additional support for this study came from Novogyne Pharmaceuticals through donation of the Vivelle-Dot ${ }^{\circledR}$ estrogen patches used in this study. The authors wish to thank Suzanne Wasylink, RNc, Debora Mordowanec, RN, Darleen DeRosa, $\mathrm{PhD}$, and Shani Osbourne, BA, for their assistance.

\section{REFERENCES}

Amin Z, Canli T, Epperson CN (2005). Effect of estrogen-serotonin interactions on mood and cognition. Behav Cogn Neurosci Rev 4: 43-58.

Anderson GM, Young JG, Cohen DJ, Schlicht KR, Patel N (1981). Liquid-chromatographic determination of serotonin and tryptophan in whole blood and plasma. Clin Chem 27: 775-776.

Bagger YZ, Tanko LB, Alexandersen P, Qin G, Christiansen C (2005). Early postmenopausal hormone therapy may prevent cognitive impairment later in life. Menopause 12: 12-17.

Benkelfat C, Ellenbogen MA, Dean P, Palmour RM, Young SN (1994). Mood-lowering effect of tryptophan depletion. Enhanced susceptibility in young men at genetic risk for major affective disorders. Arch Gen Psychiatry 51: 687-697.

Benton AL, Hamsher K, Sivan AB (1994). Multilingual Aphasia Examination. AJA Associates: Iowa City.

Billingsley RL, Simos PG, Castillo EM, Sarkari S, Breier JI, Pataraia E et al (2004). Spatio-temporal cortical dynamics of phonemic and semantic fluency. J Clin Exp Neuropsychol 26: 1031-1043.

Booij L, Van der Does W, Benkelfat C, Bremner JD, Cowen PJ, Fava $M$ et al (2002). Predictors of mood response to acute tryptophan depletion. A reanalysis. Neuropsychopharmacology 27: 852-861.
Brickman AM, Paul RH, Cohen RA, Williams LM, MacGregor KL, Jefferson AL et al (2005). Category and letter verbal fluency across the adult lifespan: relationship to EEG theta power. Arch Clin Neuropsychol 20: 561-573.

Brunner E, Domhof S, Langer F (2002). Nonparametric Analysis of Longitudinal Data in Factorial Experiments. Wiley: New York.

Cauthen NR (1978). Verbal fluency: normative data. J Clin Psychol 34: 126-129.

Delgado PL, Charney DS, Price LH, Aghajanian GK, Landis H, Heninger GR (1990). Serotonin function and the mechanism of antidepressant action. Reversal of antidepressant-induced remission by rapid depletion of plasma tryptophan. Arch Gen Psychiatry 47: 411-418.

Delgado PL, Price LH, Miller HL, Salomon RM, Aghajanian GK, Heninger GR et al (1994). Serotonin and the neurobiology of depression. Effects of tryptophan depletion in drug-free depressed patients. Arch Gen Psychiatry 51: 865-874.

Devi G, Hahn K, Massimi S, Zhivotovskaya E (2005). Prevalence of memory loss complaints and other symptoms associated with the menopause transition: a community survey. Gend Med 2: 255-264.

Drake EB, Henderson VW, Stanczyk FZ, McCleary CA, Brown WS, Smith CA et al (2000). Associations between circulating sex steroid hormones and cognition in normal elderly women. Neurology 54: 599-603.

Ellenbogen MA, Young SN, Dean P, Palmour RM, Benkelfat C (1996). Mood response to acute tryptophan depletion in healthy volunteers: sex differences and temporal stability. Neuropsychopharmacology 15: 465-474.

Epperson CN, Wisner KL, Yamamoto B (1999). Gonadal steroids in the treatment of mood disorders. Psychosom Med 65: 676-697.

Espeland MA, Rapp SR, Shumaker SA, Brunner R, Manson JE, Sherwin BB et al (2004). Conjugated equine estrogens and global cognitive function in postmenopausal women: Women's Health Initiative Memory Study. JAMA 291: 2959-2968.

First MB, Spitzer RL, Williams JBW, Gibbon M (1997). Structured Clinical Interview for DSM-IV (SCID). American Psychiatric Association: Washington, DC.

Floel A, Poeppel D, Buffalo EA, Braun A, Wu CW, Seo HJ et al (2004). Prefrontal cortex asymmetry for memory encoding of words and abstract shapes. Cereb Cortex 14: 404-409.

Gallagher P, Massey AE, Young AH, McAllister-Williams RH (2003). Effects of acute tryptophan depletion on executive function in healthy male volunteers. BMC Psychiatry 3: 10.

Golightly KL, Lloyd JA, Hobson JE, Gallagher P, Mercer G, Young AH (2001). Acute tryptophan depletion in schizophrenia. Psychol Med 31: 75-84.

Gueorguieva R, Krystal JH (2004). Move over ANOVA: progress in analyzing repeated-measures data and its reflection in papers published in the Archives of General Psychiatry. Arch Gen Psychiatry 61: 310-317.

Halbreich U, Kahn LS (2001). Role of estrogen in the aetiology and treatment of mood disorders. CNS Drugs 15: 797-817.

Halbreich U, Rojansky N, Palter S, Tworek H, Hissin P, Wang K (1995). Estrogen augments serotonergic activity in postmenopausal women. Biol Psychiatry 37: 434-441.

Hamilton M (1960). A rating scale for depression. J Neurol Neurosurg Psychiatry 23: 56-62.

Hampson E (1990a). Estrogen-related variations in human spatial and articulory-motor skills. Psychoneuroendocrinology 15: 97-111.

Hampson E (1990b). Variations in sex-related cognitive abilities across the menstrual cycle. Brain Cogn 14: 26-43.

Hampson E, Kimura D (1988). Reciprocal effects of hormonal fluctuations on human motor and perceptual-spatial skills. Behav Neurosci 102: 456-459. 
Harrison BJ, Olver JS, Norman TR, Burrows GD, Wesnes KA, Nathan PJ (2004). Selective effects of acute serotonin and catecholamine depletion on memory in healthy women. J Psychopharmacol 18: 32-40.

Henderson VW, Watt L, Buckwalter JG (1996). Cognitive skills associated with estrogen replacement in women with Alzheimer's disease. Psychoneuroendocrinology 21: 421-430.

Hogervorst E, Williams J, Budge M, Riedel W, Jolles J (2000). The nature of the effect of female gonadal hormone replacement therapy on cognitive function in post-menopausal women: a meta-analysis. Neuroscience 101: 485-512.

Kahkonen S, Ahveninen J, Pennanen S, Liesivuori J, Ilmoniemi RJ, Jaaskelainen IP (2002). Serotonin modulates early cortical auditory processing in healthy subjects: evidence from MEG with acute tryptophan depletion. Neuropsychopharmacology 27: 862-868.

Klaassen T, Riedel WJ, van Someren A, Deutz NE, Honig A, van Praag HM (1999). Mood effects of 24-hour tryptophan depletion in healthy first-degree relatives of patients with affective disorders. Biol Psychiatry 46: 489-497.

Kugaya A, Epperson CN, Zoghbi S, van Dyck CH, Hou Y, Fujita M et al (2003). Increase in prefrontal cortex serotonin 2A receptors following estrogen treatment in postmenopausal women. $\mathrm{Am} \mathrm{J}$ Psychiatry 160: 1522-1524.

LeBlanc ES, Janowsky J, Chan BK, Nelson HD (2001). Hormone replacement therapy and cognition: systematic review and metaanalysis. JAMA 285: 1489-1499.

Leube DT, Erb M, Grodd W, Bartels M, Kircher TT (2001). Differential activation in parahippocampal and prefrontal cortex during word and face encoding tasks. Neuroreport 12: 2773-2777.

Lippert TH, Filshie M, Muck AO, Seeger H, Zwirner M (1996). Serotonin metabolite excretion after postmenopausal estradiol therapy. Maturitas 24: 37-41.

Maki PM, Resnick SM (2000). Longitudinal effects of estrogen replacement therapy on PET cerebral blood flow and cognition. Neurobiol Aging 21: 373-383.

Maki PM, Zonderman AB, Resnick SM (2001). Enhanced verbal memory in nondemented elderly women receiving hormonereplacement therapy. Am J Psychiatry 158: 227-233.

Malec JF, Ivnik RJ, Hinkeldey NS (1991). Visual spatial learning test. Psychol Assess 3: 82-88.

McAllister-Williams RH, Massey AE, Rugg MD (2002). Effects of tryptophan depletion on brain potential correlates of episodic memory retrieval. Psychopharmacology 160: 434-442.

McEwen B (2002). Estrogen actions throughout the brain. Recent Prog Horm Res 57: 357-384.

McNair ML, Lorr M, Droppleman LF (1992). POMS Manual: Profile of Mood States. Edits: San Diego, CA.

McVeigh C (2005). Perimenopause: more than hot flushes and night sweats for some Australian women. J Obstet Gynecol Neonatal Nurs 34: 21-27.

Morrison MF, Kallan MJ, Ten Have T, Katz I, Tweedy K, Battistini M (2004). Lack of efficacy of estradiol for depression in postmenopausal women: a randomized, controlled trial. Biol Psychiatry 55: 406-412.

Murphy FC, Smith KA, Cowen PJ, Robbins TW, Sahakian BJ (2002). The effects of tryptophan depletion on cognitive and affective processing in healthy volunteers. Psychopharmacology 163: $42-53$

Neumeister A, Konstantinidis A, Stastny J, Schwarz MJ, Vitouch O, Willeit $\mathrm{M}$ et al (2002). Association between serotonin transporter gene promoter polymorphism (5HTTLPR) and behavioral responses to tryptophan depletion in healthy women with and without family history of depression. Arch Gen Psychiatry 59: 613-620.

Neumeister A, Praschak-Rieder N, Besselmann B, Rao ML, Gluck J, Kasper S (1997). Effects of tryptophan depletion on drug-free patients with seasonal affective disorder during a stable response to bright light therapy. Arch Gen Psychiatry 54: 133-138.
Nishizawa S, Benkelfat C, Young SN, Leyton M, Mzengeza S, de Montigny C et al (1997). Differences between males and females in rates of serotonin synthesis in human brain. Proc Natl Acad Sci USA 94: 5308-5313.

Park SB, Coull JT, McShane RH, Young AH, Sahakian BJ, Robbins TW et al (1994). Tryptophan depletion in normal volunteers produces selective impairments in learning and memory. Neuropharmacology 33: 575-588.

Peeyananjarassri K, Cheewadhanaraks S, Hubbard M, Zoa Manga R, Manocha R, Eden J (2006). Menopausal symptoms in a hospitalbased sample of women in southern Thailand. Climacteric 9: 23-29.

Phillips K, Silverman I (1997). Differences in the relationship of menstrual cycle phase to spatial performance on two- and threedimensional tasks. Horm Behav 32: 167-175.

Phillips SM, Sherwin BB (1992). Effects of estrogen on memory function in surgically menopausal women. Psychoneuroendocrinology 17: 485-495.

Rapp PR, Morrison JH, Roberts JA (2003). Cyclic estrogen replacement improves cognitive function in aged ovariectomized rhesus monkeys. J Neurosci 23: 5708-5714.

Ravdin LD, Katzen HL, Agrawal P, Relkin NR (2003). Letter and semantic fluency in older adults: effects of mild depressive symptoms and age-stratified normative data. Clin Neuropsychol 17: 195-202.

Reber PJ, Siwiec RM, Gitelman DR, Parrish TB, Mesulam MM, Paller KA (2002). Neural correlates of successful encoding identified using functional magnetic resonance imaging. J Neurosci 22: 9541-9548.

Resnick SM, Maki PM, Golski S, Kraut MA, Zonderman AB (1998). Effects of estrogen replacement therapy on PET cerebral blood flow and neuropsychological performance. Horm Behav 34: 171-182.

Reynolds RF, Obermeyer CM (2005). Age at natural menopause in Spain and the United States: results from the DAMES project. Am J Hum Biol 17: 331-340.

Rice K, Morse C (2003). Measuring cognition in menopause research: a review of test use. Climacteric 6: 2-22.

Riedel WJ, Klaassen T, Deutz NE, van Someren A, van Praag HM (1999). Tryptophan depletion in normal volunteers produces selective impairment in memory consolidation. Psychopharmacology 141: 362-369.

Riedel WJ, Sobczak S, Schmitt JA (2003). Tryptophan modulation and cognition. Adv Exp Med Biol 527: 207-213.

Rogers RD, Blackshaw AJ, Middleton HC, Matthews K, Hawtin K, Crowley C et al (1999). Tryptophan depletion impairs stimulusreward learning while methylphenidate disrupts attentional control in healthy young adults: implications for the monoaminergic basis of impulsive behaviour. Psychopharmacology 146: 482-491.

Rogers RD, Tunbridge EM, Bhagwagar Z, Drevets WC, Sahakian BJ, Carter CS (2003). Tryptophan depletion alters the decisionmaking of healthy volunteers through altered processing of reward cues. Neuropsychopharmacology 28: 153-162.

Rubinsztein JS, Rogers RD, Riedel WJ, Mehta MA, Robbins TW, Sahakian BJ (2001). Acute dietary tryptophan depletion impairs maintenance of "affective set" and delayed visual recognition in healthy volunteers. Psychopharmacology 154: 319-326.

Schmidt PJ, Nieman L, Danaceau MA, Tobin MB, Roca CA, Murphy JH et al (2000). Estrogen replacement in perimenopause-related depression: a preliminary report. Am J Obstet Gynecol 183: 414-420.

Schmitt JA, Jorissen BL, Sobczak S, van Boxtel MP, Hogervorst E, Deutz NE et al (2000). Tryptophan depletion impairs memory consolidation but improves focused attention in healthy young volunteers. J Psychopharmacol 14: 21-29.

Schnatz PF, Serra J, O'Sullivan DM, Sorosky JI (2006). Menopausal symptoms in Hispanic women and the role of socioeconomic factors. Obstet Gynecol Surv 61: 187-193. 
Shaywitz SE, Naftolin F, Zelterman D, Marchione KE, Holahan JM, Palter SF et al (2003). Better oral reading and short-term memory in midlife, postmenopausal women taking estrogen. Menopause 10: 420-426.

Sherwin BB (1988). Estrogen and/or androgen replacement therapy and cognitive functioning in surgically menopausal women. Psychoneuroendocrinology 13: 345-357.

Sherwin BB (2003). Estrogen and cognitive functioning in women. Endocr Rev 24: 133-151.

Sherwin BB, Suranyi-Cadotte BE (1990). Up-regulatory effect of estrogen on platelet ${ }^{3} \mathrm{H}$-imipramine binding sites in surgically menopausal women. Biol Psychiatry 28: 339-348.

Silverman I, Phillips K (1993). Effects of estrogen changes during the menstrual cycle on spatial performance. Ethol Sociobiol 14: 257-270.

Smith YR, Giordani B, Lajiness-O’Neill R, Zubieta JK (2001). Longterm estrogen replacement is associated with improved nonverbal memory and attentional measures in postmenopausal women. Fertil Steril 76: 1101-1107.

Soares CN, Almeida OP, Joffe H, Cohen LS (2001). Efficacy of estradiol for the treatment of depressive disorders in perimeno- pausal women: a double-blind, randomized, placebo-controlled trial. Arch Gen Psychiatry 58: 529-534.

Stewart ME, Deary IJ, Ebmeier KP (2002). Neuroticism as a predictor of mood change: the effects of tryptophan depletion. Br J Psychiatry 181: 242-247.

van Amelsvoort TA, Abel KM, Robertson DM, Daly E, Critchley H, Whitehead $\mathrm{M}$ et al (2001). Prolactin response to $d$-fenfluramine in postmenopausal women on and off ERT: comparison with young women. Psychoneuroendocrinology 26: 493-502.

Wechsler D (1987). The Wechsler Memory Scale Revised. The Psychological Corporation: San Antonio, TX.

Wolf OT, Kudielka BM, Hellhammer DH, Torber S, McEwen BS, Kirschbaum C (1999). Two weeks of transdermal estradiol treatment in postmenopausal elderly women and its effect on memory and mood: verbal memory changes are associated with the treatment induced estradiol levels. Psychoneuroendocrinology 24: 727-741.

Yaffe K, Sawaya G, Lieberburg I, Grady D (1998). Estrogen therapy in postmenopausal women: effects on cognitive function and dementia. JAMA 279: 688-695. 